\title{
INTRODUCTION
}

\section{Language Barriers in Health Care}

\author{
Somnath Saha, MD, MPH ${ }^{1,2}$ and Alicia Fernandez, $M D^{3}$
}

'Section of General Internal Medicine, Portland VA Medical Center, Portland, OR, USA; 'Division of General Internal Medicine \& Geriatrics, Oregon Health \& Science University, Portland, OR, USA; ${ }^{3}$ Department of Medicine, University of California San Francisco, San Francisco, CA, USA.

J Gen Intern Med 22(Suppl 2):281-2

DOI: $10.1007 / \mathrm{s} 11606-007-0373-3$

(c) Society of General Internal Medicine 2007

$\tau$ magine yourself in a place far from home. Perhaps you are visiting China's beautiful Yunnan Province. You are in a small town, preparing to tour a region many claim to be the fabled Shangri-La. You have had a bit of a cough for a few days, but yesterday you began feeling decidedly unwell. You feel feverish, cold, weak, light-headed. Your cough is getting worse, and you are now bringing up dark, yellowish sputum, and occasionally small amounts of blood. You feel out of breath going up just 1 flight of stairs. The right side of your chest aches with each cough.

Your partner tells your Chinese guide that you are sick and need a doctor. The guide confers with the innkeeper and then escorts you a few blocks to a nondescript, gray stone building in a narrow, cobblestone alley. Inside, the guide speaks to an elderly man in traditional clothing, who takes you both into a small room with a chair, a bench, and a table. You wait, uncertain where you are supposed to sit, until the elderly manthe doctor as it turns out-points to the bench. The doctor says a few words to the guide, in what sounds like the local dialect. The guide then turns to you and asks, using her limited English-language skills, what your symptoms are. You explain the cough and chest pain, acting out gestures to go along with your words. You say you have a fever and trouble breathing. The guide nods her head, but looks a little uncertain as she tells the doctor what (she thinks) you have said. The doctor comes around the table and places a hand on your wrist, feeling your pulse. He motions for you to stick out your tongue, which he examines for what seems like an inordinately long time. He listens briefly to your lungs with a stethoscope.

He then speaks to the guide, who nods her head continuously. After about a minute or two, the doctor finishes talking, and the guide turns to you and says, "He will give you medicine." You ask her what the doctor thinks is wrong. She thinks for a moment and says, "You have problem in here," gesturing to her chest. "Pneumonia?" you ask. "Infection?" She looks at the doctor. Neither appears to know what you are saying.

You turn to the doctor and tell him that you are allergic to penicillin. "No penicillin," you say, shaking your head vigor- ously and making an $\mathrm{X}$ with your arms. The doctor and guide look at each other and then back at you, their expressions empathetic, but helpless. You give up and make a "never mind" gesture with your hands.

You return to the inn. Later in the day, the doctor arrives with a bottle of cream-colored pills. He goes over instructions with the guide. "Are they antibiotics?" you ask. The doctor says something to the guide, who then turns to you. "It is good medicine, will make you better." You look at the pill bottle. The instructions are in Chinese characters. The guide tells you the doctor wants you to take 2 pills 3 times a day. You confer with your partner. Your bus does not go back for another 10 days. You could hire a taxi, but the nearest city is a 2-day drive. You look at the pill bottle again. You have no idea what is in it. You have no idea whether the pills will help or harm you. All you know is that you wish you could read the label, or at least talk to a doctor in your own language.

For most of us, it is difficult to feel vulnerable even if faced with an extreme situation like this one. In the current era of global "Americanization," cell phones and BlackBerrys ${ }^{\circledR}$, the internet, and post-9/11 security-mindedness, it is hard to even envision, much less experience, a scenario in which we have no English-language "lifeline" in the event of an emergency. Perhaps this is why we as a profession, an industry, and a nation continue to drag our feet in addressing the problem of language barriers in health care, despite the millions of Americans (and many more outside the United States) whose care is compromised on a daily basis by the fear, uncertainty, poor quality, and potentially life-threatening medical errors caused by the inability of doctor and patient to communicate with each other.

This Supplement provides a sliver of hope. Health care leaders, researchers, innovators, and advocates have contributed some of their best work and ideas to this collection that we believe represents the cutting edge of efforts to improve the care of Americans with limited English proficiency (LEP).

We begin with articles that remind us of the scope and magnitude of the problem. Using national data, Cheng demonstrates the degree to which language barriers interfere with the provision of basic health services. Sentell examines access to mental health care in California and reveals dramatic disparities by language. The study by Schenker raises the disturbing question of whether LEP patients are undergoing medical procedures without providing informed consent. Dohan reminds us that in many cases, language barriers actually ob- 
struct 2 channels of communication-linguistic and culturaland that the latter may be the more important. Translating the word "cancer" into other languages may be relatively simple, but grappling with its meaning in other cultures can be a much more complex endeavor.

From these articles that expose the problems posed by language barriers, we turn to a series of papers testing innovative solutions. Jacobs embeds a pair of interpreters in a hospital ward service. In 2 separate studies, Gany compares the effects of different methods of delivering interpreter services-including the United Nations-style "remote simultaneous" method-on patient satisfaction, visit duration, and miscommunication resulting in potential medical errors.

These studies, as well as another by Ngo-Metzger, also compare the use of interpreters to "language concordant" interactions, i.e., those where doctor and patient speak the same language. The results are not surprising. Even in settings with highly qualified interpreters and physicians well trained to work with them, the mere presence of a "middleperson" in a doctorpatient interaction can have a negative impact. ${ }^{1}$ However, in our predominantly monolingual nation, we know that interpreters are necessary. We also know that most people who serve as interpreters are not highly qualified, and most physicians are not well trained to work with them. ${ }^{2}$ In that vein, studies by Moreno and Lie attempt to move the field forward by developing methods to test interpreter competence and medical students' ability to effectively communicate through an interpreter.

Whereas work to improve the quality of interpreter services and use is clearly needed, we must remember that perhaps the largest barrier in the world of language barriers is the lack of motivation and resources to provide language access. Gadon helps unpack this problem by conducting focus groups with physicians and office managers in small practices across the country. The authors find that physicians are well aware of the need for language services, and that they are in fact dealing with it in whatever ways they can. However, they lack the expertise and resources to provide language access efficiently and effectively.

Recognizing this, Partida challenges us to stop expecting individual providers, practices, and health plans to each invent their own solutions to the problem of language barriers, and to invest in coordinated efforts that will allow universal access to high-quality language services. She offers examples of such efforts from both inside and outside the United States, and provides a framework for the type of infrastructure needed to support health care providers and policymakers in the care of LEP patients.

Partida's insights come from her work as Director of Hablamos Juntos, a Robert Wood Johnson Foundation (RWJF) initiative. RWJF, sponsor of this Supplement, has led the way in the search for solutions to language barriers in health care. Through Hablamos Juntos and another initiative, Speaking Together, RWJF has supported the implementation and evaluation of demonstration projects to test innovative ways of providing and ensuring high-quality language access. In the articles by $\mathrm{Wu}$ and Regenstein, we hear some of the lessons learned thus far from these important national programs.

Lastly, we view the issue of language barriers in health care through a series of different lenses. Schyve, Senior Vice
President at The Joint Commission, offers the perspective of an accrediting body concerned with the quality and safety of care delivered by health systems. Chen describes the legal landscape-reminding us that the failure to provide language access amounts to a violation of the Civil Rights Act of 1964and gives us an update on current federal and state laws. Gregg offers a conceptual framework, informed by the fields of sociolinguistics and anthropology, that provides a deeper understanding of the complexities of language barriers. Finally, we place the issue of language barriers in the context of racial and ethnic disparities in health care and discuss the role of bridging language gaps as an essential measure to reduce disparities and improve the overall health and well-being of the nation.

This JGIM Supplement represents the work of many people. We thank the authors who submitted their manuscripts, all of which represented important work, and many of which we were not able to publish. We are indebted to RWJF for making this Supplement possible, and appreciate in particular the guidance of Pam Dickson. We are grateful to the JGIM editors and staff for their support, especially Cindy Byrne, whose patience persevered despite us. We thank RWJF president and CEO Risa Lavizzo-Mourey and former Surgeon General Richard Carmona, for their leadership and advocacy. Finally, we offer special thanks to 2 people: Yolanda Partida, from whose vision this Supplement came to be; and Eliseo PerezStable, whose leadership helped shape the content of the Supplement, and whose mentorship guided us as editors.

We hope you enjoy reading this collection of work by leaders in the field of language access. More importantly, we hope you are motivated, inspired, moved to take action, so that in our offices, clinics, emergency departments, and hospitals, LEP Americans will someday get the equal treatment that is their legal right.

Acknowledgments: Dr. Saha is supported by an Advanced Research Career Development award from the Department of Veterans Affairs, Health Services Research \& Development Service, and by a Generalist Physician Faculty Scholars award from the Robert Wood Johnson Foundation. The opinions expressed in this article are those of the authors and not necessarily those of the Department of Veterans Affairs or the Robert Wood Johnson Foundation.

Conflicts of interest: None disclosed.

Corresponding Author: Somnath Saha, MD, MPH; Section of General Internal Medicine, Portland VA Medical Center (P3MED), 3710 SW U.S. Veterans Hospital Rd., Portland, OR 97239, USA (e-mail: sahas@ohsu.edu).

\section{REFERENCES}

1. Aranguri C, Davidson B, Ramirez R. Patterns of communication through interpreters: a detailed sociolinguistic analysis. J Gen Intern Med. 2006;2 (6):623-9.

2. Lee KC, Winickoff JP, Kim MK, et al. Resident physicians' use of professional and nonprofessional interpreters: a national survey. JAMA. 2006;296(9):1050-3. 